\title{
Eritrograma de bezerras sadias, da raça Holandesa, no primeiro mês de vida ${ }^{1}$
}

\author{
Fernando J. Benesi2* ${ }^{2 *}$ Cynthia M.C. Teixeira ${ }^{3}$, Júlio A.N. Lisboa ${ }^{3}$, Marta L.R. Leal ${ }^{3}$, \\ Eduardo H. Birgel Júnior ${ }^{3}$, Elizabeth Bohland ${ }^{3}$ e Regina M.S. Mirandola ${ }^{2}$
}

\begin{abstract}
Benesi F.J., Teixeira C.M.C., Lisboa J.A.N., Leal M.L.R., Birgel Jr E.H., Bohland E. \& Mirandola R.M.S. 2012. [Erytrogram of healthy female Holstein calves during the first month of life.] Eritrograma de bezerras sadias, da raça Holandesa, no primeiro mês de vida. Pesquisa Veterinária Brasileira 32(4):357-360. Departamento de Clínica Médica, Faculdade de Medicina Veterinária e Zootecnia, Universidade de São Paulo, Campus Universitário, Av. Prof. Dr. Orlando Marques de Paiva 87, São Paulo, SP 05508-000, Brazil.E-mail: febencli@usp.br

In order to establish reference values, and to assess the influence of the age factor on the erytrogram of healthy Holstein calves, blood samples from 300 animals were used, spread over 15 experimental groups, according to age, in the first month of life. Variations of the average values for the components of erytrogram were as follows: number of red blood cells $\left(\mathrm{x} 10^{6} / \mathrm{mm}^{3}\right)=6.68-7.60$, packed cell volume $(\%)=29.80-33.35$, hemoglobin concentration $(\mathrm{g} / \mathrm{dl})=9.00-10.43$, mean corpuscular volume $(\mathrm{fl})=38.93-47.68$, mean corpuscular hemoglobin $(\mathrm{pg})=11.75-14.69$, mean corpuscular hemoglobin concentration $(\%)=29.53$ $31.63 \%$ and number of reticulocytes $\left(\mathrm{x}^{3} 0^{3} / \mathrm{mm}^{3}\right)=0.00-11.86$. The influence of the age factor proved to be significant for the mean corpuscular volume, mean corpuscular hemoglobin and the number of reticulocytes.
\end{abstract}

INDEX TERMS: Erytrogram, neonatology, female calves, holstein cattle.

RESUMO.- Com a finalidade de estabelecer valores de referência e de avaliar a influência do fator etário sobre o eritrograma de bezerras sadias, da raça Holandesa, utilizaram-se amostras de sangue de 300 animais, distribuídos por 15 grupos experimentais, de acordo com a idade, no primeiro mês de vida. As variações dos valores médios obtidos para os componentes do eritrograma foram as seguintes: número de hemácias $\left(\mathrm{x}^{6} 0^{6} / \mathrm{mm}^{3}\right)=6,68-7,60$, volume globular $(\%)=29,80-33,35$, taxa de hemoglobina $(\mathrm{g} / \mathrm{dl})=9,00-10,43$, volume corpuscular médio $(\mathrm{fl})=38,93$ 47,68 , hemoglobina corpuscular média $(p g)=11,75-14,69$, concentração de hemoglobina corpuscular média $(\%)=$ 29,53-31,63\% e número de reticulócitos $\left(\mathrm{x}_{10} / \mathrm{mm}^{3}\right)=$ 0,00-11,86. A influência do fator etário provou-se significativa para o volume corpuscular médio, hemoglobina cor-

\footnotetext{
${ }^{1}$ Recebido em 16 de julho de 2011

Aceito para publicação em 22 de fevereiro de 2012

${ }^{2}$ Departamento de Clínica Médica, Faculdade de Medicina Veterinária e Zootecnia, Universidade de São Paulo (USP), Av. Prof. Dr. Orlando Marques de Paiva, 87, São Paulo, SP 05508-000, Brasil. * Autor para correspondência: febencli@usp.br

${ }^{3}$ Pós- graduando do Programa de Clínica Veterinária da FMVZ-USP.
}

puscular média e número de reticulócitos.

TERMOS DE INDEXAÇ̃̃O: Eritrograma, neonatologia, bezerras, gado holandês.

\section{INTRODUÇÃo}

A fase neonatal é decisiva para a sobrevivência dos bezerros uma vez que seu sistema imunológico encontra-se em desenvolvimento, necessitando se adaptar às grandes diferenças ambientais a que são submetidos fora do útero, sendo, portanto, este período da vida desses animais em que, reconhecidamente, estão mais sujeitos às doenças (Benesi 1992). As enfermidades que mais freqüentemente acometem os animais jovens da espécie bovina são as diarréias, inflamações umbilicais, pneumonias e septicemias que podem causar, além dos sintomas clínicos específicos, alterações hematológicas. Pesquisas que visem direta ou indiretamente o estudo dessas afecções e das modificações hematológicas provocadas nesses animais são fundamentais, pois evitam ou minoram as grandes perdas econômicas relacionadas com a morte de bezerros, principalmente de fêmeas com característica leiteira e de alto valor genético. 
A avaliação clínica dos neonatos enfermos, com vistas ao diagnóstico, prognóstico e tratamento das doenças, exige, em muitas situações, além do exame fisico, a complementação deste através de exames laboratoriais auxiliares. Incluem-se nessa avaliação como arma fundamental ao clínico, seja para confirmar ou elucidar o diagnóstico dessas enfermidades ou orientar a terapia e o prognóstico, o estudo do eritrograma (Benesi 1993).

As condições básicas para a adequada interpretação dos resultados obtidos nesses exames complementares exigem a colheita do máximo de informações através do exame físico, o conhecimento da fisiologia dos órgãos ou sistemas afetados e da patogenia das enfermidades, além da necessidade fundamental de se contar com valores de referência específicos, que considerem a espécie, a raça, a idade, o sexo e fatores ambientais/climáticos de onde vivem os animais. Apesar da consciência da necessidade para a precisa e fundamentada interpretação dos resultados obtidos com a avaliação do eritrograma, raras foram as pesquisas nacionais realizadas com este mister, ou seja, o estabelecimento de valores de referência em neonatos da espécie bovina criados em condições brasileiras, destacando-se aquelas realizadas por Benesi (1992), Biondo (1996) e Fagliari et al. (1998).

No entanto, em nenhum desses trabalhos avaliou-se o eritrograma de recém-nascidos de raças leiteiras com o detalhamento exigido considerando o período em que há grandes variações fisiológicas do neonato para a sua adaptação ao meio extra-uterino e seus possíveis reflexos sobre o quadro hematológico, assim sendo, o estudo proposto nesta pesquisa é fundamental para cobrir esta lacuna na literatura nacional, pois tem por objetivo estabelecer valores de referência para o eritrograma de bezerras sadias, da raça Holandesa, no primeiro mês de vida, criadas em fazendas produtoras de leite do Estado de São Paulo, bem como avaliar a influência do fator etário sobre as variações dos componentes do eritrograma.

\section{MATERIAL E MÉTODOS}

Foram utilizadas 300 bezerras sadias, da raça Holandesa, com até 30 dias de vida, oriundas de fazendas produtoras de leite dos tipos A e B localizadas no Estado de São Paulo. As bezerras foram distribuídas por 15 grupos experimentais, cada um com 20 animais, de acordo com a faixa etária: do nascimento até 8 horas de vida; de 9 até 16 horas; de 17 até 24 horas; 2 dias de idade; 3 dias; 4 dias; 5 dias; 6 e 7 dias; 8 e 9 dias; 10 e 11 dias; 12 e 13 dias; 14 e 15 dias; de 16 a 20 dias; de 21 a 25 dias; e de 26 a 30 dias de vida.

Os animais selecionados para o experimento ainda não haviam sido submetidos a programas de premunição contra Babesia spp. e Anaplasma sp., e foram considerados clinicamente sadios, após o exame clínico (Dirksen et al. 1993). Foram excluídos do experimento os animais que apresentaram volume globular inferior a $25 \%$ ou superior a $40 \%$.

As amostras de sangue foram obtidas através de punção da veia jugular externa com a utilização de um sistema a vácuo, em tubo siliconizado com EDTA tripotássico na proporção de $1,5 \mathrm{mg} / \mathrm{ml}$ de sangue (capacidade para $5 \mathrm{ml}$ de sangue) e agulha para múltiplas colheitas $(25 \mathrm{~mm} \times 8 \mathrm{~mm})$ do sistema Vacutainer®. Esfregaços sanguíneos para as contagens de re- ticulócitos foram confeccionados com sangue fresco sem anticoagulante, recebendo coloração segundo técnicas propostas por Birgel (1982), sendo a diferenciação dos mesmos realizada durante a contagem de 1000 eritrócitos observados (Birgel 1982, Jain 1986).

A hemoglobina $(\mathrm{Hb})$ foi analisada por método colorimétrico segundo a técnica da cianometahemoglobina. A determinação do volume globular (VG) e a contagem total de hemácias (He) foram realizadas respectivamente, pelo micrométodo e pelas contagens das células manualmente em hemocitômetro de Neubauer modificado (Birgel 1982). A partir dos valores obtidos para o número de hemácias, a taxa de hemoglobina e volume globular foram calculados os índices hematimétricos absolutos: Volume Corpuscular Médio (VCM), Hemoglobina Corpuscular Média (HCM) e Concentração de Hemoglobina Corpuscular Média (CHCM).

O efeito do fator etário sobre os componentes do eritrograma foi verificado por meio da análise de variância (ANOVA) considerando-se um experimento inteiramente aleatório. Quando a estatística F resultou significativa, verificaram-se os contrastes entre médias com o emprego do teste de Tukey, calculando-se a diferença mínima significativa, e admitindo-se uma probabilidade de erro de 5\% (Berquó et al. 1981). Apresentaram-se a média e o desvio padrão como as medidas de tendência central e de dispersão para as variáveis estudadas.

\section{RESULTADOS}

Os valores dos componentes do eritrograma: $\mathrm{He}, \mathrm{VG}$ e $\mathrm{Hb}$ estão representados no Quadro 1. 0 número de hemácias $(\mathrm{He})$ apresentou um valor mínimo, próximo ao nascimento (9 a 16 horas pós-nascimento), enquanto os valores máximos do volume globular (VG) e da taxa de hemoglobina $(\mathrm{Hb})$ foram demonstrados, respectivamente, até 8 horas p.n. e aos 4 dias p.n.. A seguir, os valores dessas determinações evoluíram com tendências a aumento para o He e a diminuições para o VG e a $\mathrm{Hb}$, atingindo valores máximos para o He entre 16 e 20 dias pós nascimento e mínimos para o VG e a $\mathrm{Hb}$, ao final de um mês de vida.

Os resultados obtidos para os índices hematimétricos absolutos (Quadro 2), permitiram evidenciar que o Volume Corpuscular Médio e a Hemoglobina Corpuscular Média demonstraram comportamento semelhante, ou seja, com

Quadro 1. Valores médios e respectivos desvios padrão $(\mathrm{x} \pm \mathrm{s})$ obtidos para o número de hemácias (He), volume globular (VG) e taxa de hemoglobina ( $\mathrm{Hb}$ ), no sangue de bezerras sadias, da raça Holandesa, agrupadas de acordo com a idade

\begin{tabular}{cccccc}
\hline Grupo & Idade & $\mathrm{n}^{\circ}$ & $\mathrm{He}\left(10^{6} / \mathrm{mm}^{3}\right)$ & $\mathrm{VG}(\%)$ & $\mathrm{Hb}(\mathrm{g} / \mathrm{dl})$ \\
\hline 1 & até 8 horas & 20 & $7,02 \pm 0,86$ & $33,35 \pm 4,92$ & $10,05 \pm 1,79$ \\
2 & 8 a 16 horas & 20 & $6,68 \pm 1,15$ & $31,55 \pm 4,24$ & $9,74 \pm 1,53$ \\
3 & 16 a 24 horas & 20 & $7,03 \pm 1,12$ & $32,40 \pm 4,21$ & $10,01 \pm 1,53$ \\
4 & 2 dias & 20 & $6,73 \pm 1,03$ & $31,25 \pm 5,40$ & $9,84 \pm 1,58$ \\
5 & 3 dias & 20 & $7,18 \pm 1,33$ & $32,40 \pm 4,84$ & $10,19 \pm 01,45$ \\
6 & 4 dias & 20 & $7,31 \pm 1,18$ & $33,30 \pm 4,65$ & $10,43 \pm 1,63$ \\
7 & 5 dias & 20 & $6,70 \pm 1,09$ & $30,85 \pm 3,47$ & $9,49 \pm 1,22$ \\
8 & 6 e 7 dias & 20 & $7,13 \pm 1,25$ & $31,90 \pm 4,40$ & $9,71 \pm 1,73$ \\
9 & 8 e 9 dias & 20 & $7,47 \pm 1,27$ & $32,60 \pm 4,59$ & $9,88 \pm 1,41$ \\
10 & 10 e 11 dias & 20 & $7,30 \pm 0,94$ & $31,05 \pm 3,28$ & $9,68 \pm 1,37$ \\
11 & 12 e 13 dias & 20 & $7,20 \pm 1,10$ & $31,30 \pm 4,88$ & $9,74 \pm 1,85$ \\
12 & 14 e 15 dias & 20 & $7,31 \pm 0,93$ & $31,00 \pm 4,25$ & $9,73 \pm 1,47$ \\
13 & 16 a 20 dias & 20 & $7,60 \pm 1,25$ & $32,00 \pm 4,55$ & $9,56 \pm 1,78$ \\
14 & 21 a 25 dias & 20 & $7,43 \pm 1,16$ & $30,70 \pm 3,73$ & $9,11 \pm 1,64$ \\
15 & 26 a 30 dias & 20 & $7,13 \pm 0,89$ & $29,80 \pm 2,67$ & $9,00 \pm 1,24$
\end{tabular}


Quadro 2. Valores médios e desvios padrão $(x \pm s)$ obtidos para o volume corpuscular médio (VCM), hemoglobina corpuscular média (HCM), concentração de hemoglobina corpuscular média (CHCM) e reticulócitos (Ret) no sangue de bezerras sadias, da raça Holandesa, agrupadas de acordo com a idade

\begin{tabular}{|c|c|c|c|c|c|c|}
\hline Grupo & Idade & no & VCM (fl) & HCM (pg) & CHCM (\%) & $\operatorname{Ret}\left(10^{3} / \mathrm{mm}^{3}\right)$ \\
\hline 1 & até 8 horas & 20 & $47,62^{a} \pm 5,46$ & $14,42^{\mathrm{ab}} \pm 2,48$ & $30,24 \pm 3,64$ & $0,63^{\mathrm{cd}} \pm 1,95$ \\
\hline 2 & 8 a 16 horas & 20 & $47,68^{a} \pm 04,42$ & $14,69^{a} \pm 1,56$ & $30,83 \pm 1,85$ & $1,74^{\mathrm{cd}} \pm 3,22$ \\
\hline 3 & 16 a 24 horas & 20 & $46,81^{\mathrm{ab}} \pm 7,11$ & $14,44^{\mathrm{ab}} \pm 2,31$ & $30,84 \pm 1,91$ & $1,38^{\mathrm{cd}} \pm 6,17$ \\
\hline 4 & 2 dias & 20 & $46,61^{\mathrm{ab}} \pm 5,17$ & $14,69^{a} \pm 1,51$ & $31,63 \pm 2,16$ & $2,59^{\mathrm{cd}} \pm 7,03$ \\
\hline 5 & 3 dias & 20 & $45,52^{\mathrm{ab}} \pm 4,32$ & $14,36^{\mathrm{ab}} \pm 1,63$ & $31,52 \pm 1,55$ & $9,53^{\mathrm{ab}} \pm 14,13$ \\
\hline 6 & 4 dias & 20 & $45,88^{\mathrm{ab}} \pm 3,92$ & $14,33^{\mathrm{ab}} \pm 1,21$ & $31,35 \pm 2,23$ & $8,64^{\mathrm{abc}} \pm 12,02$ \\
\hline 7 & 5 dias & 20 & $46,59^{\mathrm{ab}} \pm 5,22$ & $14,32^{\mathrm{ab}} \pm 1,65$ & $30,79 \pm 2,27$ & $11,86^{\mathrm{a}} \pm 17,21$ \\
\hline 8 & 6 e 7 dias & 20 & $45,54^{\mathrm{ab}} \pm 7,67$ & $13,69^{a b c} \pm 1,83$ & $30,32 \pm 3,20$ & $4,67^{b c} \pm 13,17$ \\
\hline 9 & 8 e 9 dias & 20 & $44,10^{\mathrm{ab}} \pm 4,99$ & $13,38^{\mathrm{abc}} \pm 1,68$ & $30,36 \pm 1,81$ & $1,76^{\mathrm{cd}} \pm 3,87$ \\
\hline 10 & 10 e 11 dias & 20 & $42,78^{\mathrm{abc}} \pm 4,17$ & $13,34^{\mathrm{abc}} \pm 1,85$ & $31,14 \pm 2,90$ & $1,77^{\mathrm{cd}} \pm 3,93$ \\
\hline 11 & 12 e 13 dias & 20 & $43,70^{\mathrm{ab}} \pm 4,81$ & $13,54^{\mathrm{abc}} \pm 1,61$ & $31,00 \pm 2,25$ & $0,76^{\mathrm{cd}} \pm 2,34$ \\
\hline 12 & 14 e 15 dias & 20 & $42,51^{\mathrm{abc}} \pm 3,72$ & $13,36^{\mathrm{abc}} \pm 1,53$ & $31,42 \pm 2,36$ & $0,37^{\mathrm{cd}} \pm 1,65$ \\
\hline 13 & 16 a 20 dias & 20 & $42,53^{\mathrm{abc}} \pm 4,68$ & $12,69^{\mathrm{bcd}} \pm 1,91$ & $29,78 \pm 2,31$ & $0,79^{\mathrm{cd}} \pm 3,55$ \\
\hline 14 & 21 a 25 dias & 20 & $41,65^{b} \pm 4,08$ & $12,30^{\mathrm{bc}} \pm 1,71$ & $29,53 \pm 2,47$ & $0,00^{\mathrm{d}} \pm 0,00$ \\
\hline 15 & 26 a 30 dias & 20 & $38,93^{c} \pm 4,07$ & $11,75^{d} \pm 1,59$ & $30,21 \pm 3,15$ & $1,22^{\mathrm{cd}} \pm 4,19$ \\
\hline
\end{tabular}

valores máximos, respectivamente, entre 9 e 16 horas de vida e com 2 dias de vida, declinando gradativamente com a evolução etária e atingindo valores mínimos e significativamente menores, entre 26 e 30 dias de vida. Em relação aos valores da Concentração de Hemoglobina Corpuscular Média (Quadro 2) pode-se observar um comportamento caracterizado por pequenas variações, sem demonstração de diferenças estatisticamente significativas entre grupos etários, tendo um valor máximo aos 2 dias de vida e um mínimo entre 21 e 25 dias p.n.

Finalmente, na avaliação dos resultados registrados para a contagem do número de reticulócitos (Quadro 2) foi verificado que a presença destas células eritrocitárias imaturas ocorreu com aumentos significativos entre o terceiro e o quinto dia de vida das bezerras, com um valor máximo no último dia. Com o avançar da idade, houve uma queda significativa dessas células, que desapareceram da circulação sangüínea entre 21 e 25 dias de vida.

\section{DISCUSSÃO}

Os valores dos componentes do eritrograma, He, VG e Hb, mostraram magnitude compatível com aquelas assinaladas para o eritrograma em pesquisas realizadas em neonatos bovinos de raças leiteiras (Kraft 1967, Birgel 1972, Tennant et al. 1974, Benesi 1992). Todavia, apresentaram variações que não tiveram comportamentos similares para os três componentes do eritrograma retro mencionados. Tais variações não foram em nenhum momento influenciadas pelo fator etário (Quadro 1). Assim sendo, estas observações só puderam repetir parcialmente aquelas presentes na literatura, que destacaram que os valores máximos dos componentes do eritrograma foram evidenciados no momento do parto e nas primeiras horas p.n. (Kraft 1967, Birgel 1972, Tennant et al. 1974, Bergfeld et al. 1977, McMurray et al. 1978, Marschang 1986, Adams et al. 1992, Benesi 1992, Biondo 1996), sugerindo que este fato poderia estar relacionado ao momento exato da colheita de amostras de sangue no grupo de animais com idade entre o nascimento e 8 horas de vida, que nunca foi imediata ao nascimento e na maioria das vezes, após a primeira mamada do colostro. A evolução dos valores do VG e da $\mathrm{Hb}$, com tendência a diminuição dos valores com a progressão da idade até um mês de vida, também verificada por Rocha et al. (2010) em bezerros da raça holandesa, não foi assinalada por outros autores, que a constataram até os dois dias de vida (Tennant et al. 1974, Adams et al. 1992, Benesi 1992) ou até o final da primeira semana de vida (Kraft 1967, Birgel 1972, Fagliari et al. 1998).

As cogitações sobre as possíveis causas das diminuições dos componentes do eritrograma observadas no período neonatal estariam relacionadas provavelmente ao efeito hemodiluidor determinado pelas proteínas absorvidas do colostro que ganhariam o sangue circulante (Adams et al. 1992, Benesi 1992, Jain 1993) e à intensa metabolização dos eritrócitos fetais não compensada por adequada produção e renovação destas células, caracterizando a chamada "anemia fisiológica" (Wise 1947, Tennant et al. 1974). Contrariando está última hipótese, Birgel (1972) não encontrou evidências bioquímicas de possível crise hemolítica, reforçando-se as cogitações de que além do efeito hemodiluidor do colostro, haveria uma menor resposta da medula do neonato, devido ao aumento dos níveis sangüíneos de oxigênio no sangue em relação aos do período fetal, fatos que favoreceriam a diminuição dos componentes do eritrograma no sangue (Adams et al. 1992, Jain 1993).

A comparação dos comportamentos do Volume Corpuscular Médio e Hemoglobina Corpuscular Média com aqueles observados na literatura evidenciam que resultados similares foram obtidos em muitas pesquisas precedentes, pois nestas, logo após o nascimento, os valores do Volume Corpuscular Médio e da Hemoglobina Corpuscular Média mostraram-se elevados, diminuindo com o aumento da idade do neonato (Baglioni et al. 1956, Birgel 1972, Tennant et al. 1974, Lumsden et al. 1980, Adams et al. 1992, Benesi 1992), embora tenham divergido daqueles registrados por Kaneko \& Mills (1970) e Biondo (1996) os quais presenciaram um Volume Corpuscular Médio que tendeu a se elevar após o nascimento. Interessante notar que Rocha 
et al (2010) encontraram diferenças no comportamento do Volume Corpuscular Médio e da Hemoglobina Corpuscular Média quando os bezerros eram nascidos de vacas primíparas e multíparas, tendo os últimos apresentado um aumento destes índices com o avançar da idade.

Em linhas gerais os resultados obtidos para a Concentração de Hemoglobina Corpuscular Média são concordes com aqueles apresentados na literatura, na qual esse índice é caracterizado como tendo pequenas oscilações do nascimento até um mês de vida (Holman 1956, Kaneko \& Mills 1970, Tennant et al. 1974, Adams et al. 1992, Rocha et al. 2010).

Os maiores valores de reticulócitos encontrados entre o terceiro e quinto dia pós nascimento, concordam parcialmente com aqueles apresentados por alguns autores que relataram a observação de reticulócitos em números diminutos, em particular nos três primeiros dias de vida dos bezerros (Tennant et al. 1974, Benesi 1992). Em contrapartida, divergiram daquelas realizadas por Kraft (1967) que demonstrou somente alguns reticulócitos em animais isolados, e por Greatorex (1954) que relatou a ausência destas células em todos os animais com idade entre o nascimento e 1 ano de vida. As observações de Biondo (1996) caracterizadas por alta freqüência de aparecimento de reticulócitos, ou seja, presentes em mais de $80 \%$ dos bezerros da raça Nelore com idade entre 0 e 3 dias, seguido por gradativa diminuição de freqüência até 30 dias de vida, podem ser consideradas em números absolutos médios similares àqueles observados nesta pesquisa.

Os resultados desta pesquisa permitem concluir que os valores do VCM, do HCM e do número de reticulócitos apresentaram variações influenciadas pelo fator etário. Os menores valores observados para o número de hemácias, volume globular e a taxa de hemoglobina nos primeiros dois dias de vida das bezerras, podem ser atribuídos ao efeito hemodiluidor exercido pelas proteínas osmoticamente ativas absorvidas a partir do colostro mamado. Por outro lado, os menores valores médios para esses componentes do eritrograma, observados entre 3 e 4 dias de vida, ocorreu em decorrência da provável eritroregeneração evidenciada através do aumento significativo do número de reticulócitos, e dos valores do VCM e HCM, em mesmo período de vida pós-nascimento.

\section{REFERÊNCIAS}

Adams R., Garry F. B., Aldridge B. M., Holland M. D. \& Odde K. G. 1992. Hematologic values in newborn beef calves. Am. J. Vet. Res. 53:944-950.

Baglioni T., Locatelli A. \& Quarenghi F. 1956. Il quadro ematologico nella prima settimana di vita del vitello. La Clin. Vet. 79:289-297.

Benesi F. J. 1992. Hematologia de bezerros recém-nascidos. Influência da asfixia neonatal, do tipo do parto e da ingestão de colostro sobre a crase sanguínea. Tese de Livre-Docência, Faculdade de Medicina Veterinária e Zootecnia, Universidade de São Paulo, São Paulo, SP. 126 p.
Benesi F. J. 1993. Síndrome asfixia neonatal dos bezerros. Importância e avaliação crítica. Arq. Esc. Med. Vet. Univ. Fed. Bahia 16:38-48.

Bergefeld E., Weniger J.H. \& Steinhauf D. 1977. Veraenderungen des Blutvolumens unteer Belastung beim Schwein. Züchtungskunde 49:43-48.

Berquó E.S., Souza J.M.P. \& Gotlieb S.L.D. 1981. Bioestatística. 2ª ed. Editora Pedagógica e Universitária, São Paulo. 350p.

Biondo A.W. 1996. Hemograma de bovinos sadios da raça Nelore no primeiro mês de vida, criados no estado de São Paulo: influência de fatores etários e sexuais. Dissertação de mestrado em Clínica Médica Veterinária, Universidade Federal de Santa Maria, Santa Maria, RS. 76p.

Birgel E.H. 1972. Hämatologische Untersuchungen bei Kälbern der Rasse "Deutches Schwarzbuntes Rind" in den ersten 14 Lebenstagen. Tese de Doutorado em Ginecologia e Obstetricia, Tierärztiche Hochschule Hannover, Hannover. 89p.

Birgel E. . 1982. Hematologia clínica veterinária, p.2-49. In: Birgel E.H. \& Benesi F.J. (Eds), Patologia Clínica Veterinária. Sociedade Paulista de Medicina Veterinária, São Paulo.

Dirksen G., Gründer H.D. \& Stöber M. 1993. Rosenberger Exame Clínico dos Bovinos. $3^{\text {a }}$ ed. Guanabara Koogan, Rio de Janeiro. 419p.

Fagliari J.J., Santana A.E., Lucas F.A., Campos Filho E. \& Curi P.R. 1998. Constituintes sangüíneos de bovinos recém-nascidos das raças Nelore (Bos indicus) e Holandesa (Bos taurus) e de Bubalinos (Bubalus bubalis) da raça Murrah. Arq. Bras. Med. Vet. Zootec. 50:253-262.

Greatorex J.C. 1954. Studies on the haematology of calves from birth to one year of age. Brit. Vet. J. 110:120-133.

Holman H.H. 1956. Changes associeted with age in the blood picture of calves and heifers. Brit. Vet. J. 112:91-104.

Jain N.C. 1986. Cattle normal hematology with comments on response to disease, p.178-207. In: Jain N.C. (Ed.), Schalm's Veterinary Hematology. Lea and Febiger, Philadelphia.

Jain N.C. 1993. Essentials of Veterinary Hematology. $4^{\text {th }}$ ed. Lea and Febiger, Philadelphia, 407p.

Kaneko J.J. \& Mills R. 1970. Hematological and blood chemical observations in neonatal normal and porphyric calves in early life. Cornell Vet. 60:52-60.

Kraft W. 1967. Das Blutbild des Kalbes in der ersten zehn Lebenstagen. Dtsch. Tierärztl. Wochenschr. 74: 194-197.

Lumsden J.H., Mullen K. \& Rowe R. 1980. Hematology and biochemistry reference values for female Holstein cattle. Can. J. Comp. Med. 144:2431.

Marschang F. 1986. Stress aus tierärztlicher Sicht. Prakt. Tierarzt 67:10501052.

McMijrray C.H, Logan E.F., McParland P.J., McRory F.J. \& O'Neill O.G. 1978. Sequential changes in some blood components in the normal neonatal calf. Brit. Vet. J. 134:590-597.

Rocha T.G., Franciosi C., Nociti R.P., Nogueira C.A.S. \& Fagliari J.J. 2010. Hemograma e proteínas do soro sanguíneo de bezerros Canchim-Nelore e da raça Holandesa nos primeiros 30 dias de vida. Arq. Bras. Med. Vet. Zootec. 62:1250-1254.

Tennant B., Harrold D. \& Reina-Guerra M. 1974. Haematology of the neonatal calf: Erithrocyte and leukocyte values of normal calves. Cornell Vet. 64:516-532.

Wise G.H., Caldwell M.J., Parrish D.B., Flipse R.J. \& Hughes S. 1947. Changes in cell volume and concentration of hemoglobin and of several inorganic constituents of the blood of calves during early postnatal development. J. Dairy Sci. 30:983-993. 